\title{
Phytosanitary technologies in ensuring independence and competitiveness of the agricultural sector of Russia
}

\section{Preface}

All-Russian Institute of Plant Protection (VIZR) is celebrating its 90th anniversary in 2019. The main mission of the Institute is providing the scientific background for the food security in Russia. In the Institute we undertake the research in almost all areas related to crop protection, ranging from the fundamental biology to the development of measures, methods and systems of plant protection. We are proud to continue the work started by the founder of our Institute N.I. Vavilov and his associates.

The important component of our work is organizing the activities, where participants can share the achieved results, discuss them, inspire with new ideas and establish creative and business contacts. Scientific events in the form of the All-Russian Plant Protection Congress have been held by the initiative of VIZR in Saint Petersburg since 1995. The previous III Congress was held in December, 2013 and gathered nearly 200 participants. The number of attendees of the IV Plant Protection Congress in September 9-11, 2019 exceeded 400.

The scientific program of the Congress has covered all traditional areas of the research in the field of plant protection, which are as follows: (1) monitoring of harmful and useful objects; (2) chemical, biological methods and integrated plant protection systems; (3) plant immunity; (4) agricultural biotechnology; (5) economy and agro-engineering issues.

A plenary session, 12 contributed sessions, two workshops, a poster session and a special meeting on the biological control of the greenhouse pests have been organized. For the first time the Congress hosted an exhibition of the scientific laboratory equipment and products for plant protection, including biopesticides, chemical formulations, entomophages etc.

As many as 210 reports have been presented and discussed involving participants from Azerbaijan, Belarus, Bulgaria, Denmark, Germany, Georgia, Finland, Hungary, India, Iran, Japan, Kazakhstan, Mexico, Norway, Poland, Russia, Sweden, UK, Ukraine, US and Uzbekistan. The selected papers are published in the present issue.

The Chair of the Program Committee

Philipp Gannibal

Ph.D., Director of All-Russian Institute of Plant Protection, Saint Petersburg, Russia

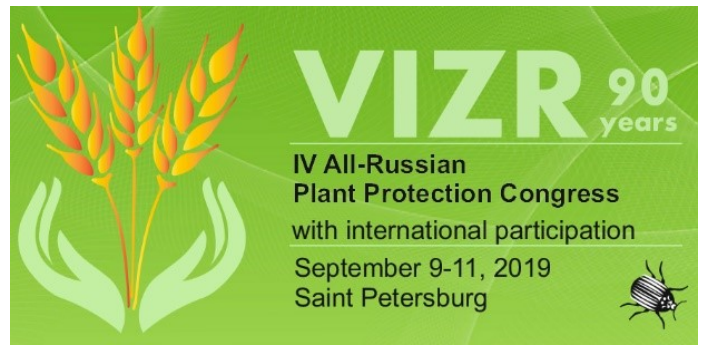

http://vizrcongress2019.ru/en/home/ 